\title{
Factors that may continue to impact a mother's emotional wellbeing once her child's treatment for cancer has completed and their implications for ongoing support
}

\begin{abstract}
This research explores factors that may continue to impact a mother's emotional wellbeing once her child's treatment for cancer has completed. Research indicates that, contrary to a general expectation of experiencing joy as treatment ends, some families experience very mixed emotions, with fear playing a large part, both leading up to treatment completion and, for some, continuing post-treatment. However, there is no literature that explores a mother's emotional wellbeing after a number of years' post-treatment. This research is a contribution towards addressing that deficit. Five mothers were interviewed using semistructured questions to gather data relating to their specific lived experiences. These were analysed using Interpretative Phenomenological Analysis. Results indicate that although end of treatment was longed for, there continues to be much uncertainty and fear posttreatment, and this can continue years after treatment has ended. Mothers described changes within themselves (e.g. new attitudes to living) and a need to adapt to a 'new normal'. There were elements of grief for the loss of family life with which they were once so familiar. There was also a strong sense of wanting to support others, so that their own experiences weren't wasted. All participants recognised that further counselling support for themselves would be beneficial.
\end{abstract}

Keywords: Mother; emotional wellbeing; childhood cancer; treatment completed; counselling

\section{Author Biographies}

Lynda Hill, MA, is Head of Adult Therapeutic Services and Research at The Joshua Tree.

Peter M. Gubi, PhD, ThD, DMin, is Professor of Counselling at the University of Chester, UK. 


\section{Introduction}

Childhood cancer is rare, accounting for approximately $2 \%$ of all cancers (Children's Cancer and Leukaemia Group (CCLG), 2019). However, a diagnosis of childhood cancer can have a huge impact on the whole family, both during treatment and long after treatment has been completed (Wakefield et al., 2011). Whilst there is now an $82 \%$ survival rate overall for childhood cancers (CCLG, 2019), there is a concern about the consequent and long-term effects of medication post-treatment - generally referred to as 'late effects' (Zheng et al., 2018). These are chronic conditions occurring or persisting five years after being diagnosed with cancer (National Cancer Institute, 2019). Approximately $60 \%$ of patients have at least one late effect. These can be physical, psychological or social (CCLG, 2019). When treatment has completed, it is expected to be celebrated by families, but it is often also a time of psychological vulnerability for parents (Wakefield et al., 2011), and parents of children diagnosed with cancer may experience symptoms without actually being diagnosed with Post Traumatic Stress Disorder (Bruce, 2005).

This research explores mothers' emotional wellbeing after their children have completed treatment for cancer. Due to the complicated, life-threatening, intensive and aggressive nature of the treatment for childhood cancers, it is well-documented that the stress put upon families during treatment is immense (Marusak, 2018). However, much of the support offered to families occurs during the treatment stage, and once treatment has finished, this support can decline (Wakefield et al., 2011). As many more children are surviving, this is leading to different issues post-treatment. After-care clinic appointments continue to be a life-long necessity due to the essential monitoring of possible late effects and cancer recurrence. As the assumed likely primary care-givers in many cases, this enquiry focusses specifically on the emotional wellbeing of mothers, post-treatment (i.e. after active 
treatment has ended), rather than after a diagnosis is received or the period during treatment.

The research question is, 'what factors continue to impact a mother's emotional wellbeing once her child's treatment for cancer has completed, and what might the implications be for continuing emotional support?' The aim is to give mothers a voice to tell their stories of how they felt after their children's treatment for cancer came to an end and to provide an opportunity for them to explore and share the impact that the illness has had as time continues to pass since completion of treatment. This will help gain further insight into the emotional wellbeing of mothers and ascertain what support at this time may be beneficial for future wellbeing. This study has not been undertaken before.

\section{Method}

After gaining permission, five participants (P1-P5) were recruited by advertising on The Joshua Tree's website (a children's cancer charity) (www.thejoshuatree.org.uk), together with their Facebook and Twitter pages. Only five responded to the adverts. There was deliberately no time restriction regarding how many years the child had reached posttreatment as we wanted to explore how varied this was in relation to the respondents. We did not include bereaved mothers. At the time of study, the child needed to be well (i.e. not on active cancer treatment or on treatment for relapse) and post-treatment. An information sheet was provided. Interview questions were given in advance of the session taking place. A consent form was signed by each participant. Participants had an opportunity, if they wished, to member-check their transcripts. Everyone was offered a de-brief session postinterview to ensure they had the opportunity to talk through anything that may have been stirred up for them during the interview process. The questions included: 
- Tell me about how you felt leading up to your child's treatment completion;

- Now treatment has ended, tell me about your feelings since finishing treatment and whether these have altered over the weeks / months / years;

- Tell me about what you feel has impacted you the most since treatment has completed;

- Have you accessed any type of support?

- What type of support would now be beneficial for you and why?

The semi-structured interviews were recorded, transcribed verbatim and analysed using Interpretative Phenomenological Analysis (Smith et al., 2009). This method is concerned with personal perception rather than with the formation of objective statements and seeks an insider perspective. A small sample size was used to enable an in-depth understanding of the phenomena. The findings add the voices of the participants, giving the data a rich texture.

\section{Findings}

The data from the five participant interviews are presented under the following superordinate and subordinate themes (see Table 1 below).

Table 1: Superordinate and Subordinate Themes

\begin{tabular}{|c|c|c|c|c|}
\hline Superordinate theme & 1 & \multicolumn{3}{|c|}{ Contextual data } \\
\hline \multirow{4}{*}{ Subordinate themes } & & 1.1 & \multicolumn{2}{|l|}{ Type of childhood cancer } \\
\hline & & 1.2 & \multicolumn{2}{|l|}{ Age of child at diagnosis } \\
\hline & & 1.3 & \multicolumn{2}{|l|}{ Length of treatment } \\
\hline & & 1.4 & \multicolumn{2}{|c|}{ Amount of time since completion of treatment } \\
\hline Superordinate theme & 2 & \multicolumn{3}{|c|}{ Feelings leading up to treatment completion } \\
\hline Subordinate Themes & & 2.1 & \multicolumn{2}{|l|}{ Mixed feelings } \\
\hline & & 2.2 & \multicolumn{2}{|l|}{ Importance of end date } \\
\hline & & 2.3 & \multicolumn{2}{|l|}{ Fear of relapse } \\
\hline Superordinate theme & 3 & \multicolumn{3}{|c|}{ Feelings since finishing treatment } \\
\hline Subordinate themes & & 3.1 & Changed self & \\
\hline & & & 3.1 .1 & Philosophical self \\
\hline
\end{tabular}




\begin{tabular}{|c|c|c|c|c|}
\hline & & $\begin{array}{l}3.4 \\
3.5 \\
3.6 \\
3.7\end{array}$ & $\begin{array}{l}\text { Longing for normality } \\
\text { Sense of abandonment / } \\
\text { limbo } \\
\\
\\
\\
\text { Underlying continued fear } \\
3.3 .1 \\
3.3 .2 \\
\text { Effect on siblings } \\
\text { Side-effects of treatment } \\
\text { Hope }\end{array}$ & $\begin{array}{l}\text { Of self } \\
\text { From hospital } \\
\text { From friends }\end{array}$ \\
\hline Superordinate theme & 4 & \multicolumn{3}{|l|}{ Support } \\
\hline Subordinate themes & & $\begin{array}{l}4.1 \\
4.2\end{array}$ & \multicolumn{2}{|c|}{$\begin{array}{l}\text { Recognition should really access support } \\
\text { Wanting to help others }\end{array}$} \\
\hline
\end{tabular}

\section{Superordinate theme 1: Contextual data}

\section{Subordinate theme 1.1: Type of childhood cancer}

Of the five participants, two children were diagnosed with blood cancers. Both experienced relapse (P1, P2). The remaining three children had brain tumours (P3, P4, P5).

\section{Subordinate theme 1.2: Age of child at diagnosis}

Four children were in the age category, 2-5 years. One child was seven years old ( $\mathrm{P} 4)$.

\section{Subordinate theme 1.3: Length of treatment}

The blood cancer treatments were both over two years. A further period of treatment was accessed after relapse (ten months for P1 and four months for P2). The treatment for brain tumours was seven months (P5), eighteen months (P4) and just under two years (P3).

Subordinate theme 1.4: Amount of time since completion of treatment 
Taking completion of the first diagnosis as the point of reference, four of the five participants were between three and five-and-a-half years off treatment, and one participant was just two months off treatment (P5).

\section{Superordinate theme 2: Feelings leading up to treatment completion}

\section{Subordinate theme $2.1 \quad$ Mixed feelings}

All participants experienced mixed emotions leading up to their child's completion of treatment:

'There was elation that she was finally going to come off all the medication... we tried just to stay really positive... [however we] were just full of fear as soon as the treatment stopped that the Leukaemia would come back. So, it was completely mixed feelings...' (P1).

'We were really nervous. The concerns we had were, was this going to work? Has this worked? Is it going to save him?' (P2).

'Towards the end of his treatment it was almost like - ooo - we might get to go home a few weeks early. This is brilliant... I was really excited on the phone but when I got off the phone, I was actually frightened of him coming home. I felt this is ridiculous, you know. He's been in for so long now... I almost felt like I was trying to delay it and I started to feel frightened and I'd never admit this to anyone but I just felt, I panicked I think..., thinking 'what if I can't cope? what if he can't cope?' (P5).

\section{Subordinate theme 2.2: Importance of the end date of treatment}

Both P3 and P4 focussed on the importance they put on the end date.

'I remember feeling desperate it wouldn't be delayed' (P3).

'All I could focus on was that date - just thinking we've got less time when that date is finally coming. This whole ordeal will be over and everything will be back to normal' (P4).

Subordinate theme 2.3: Fear of relapse 
The overriding feeling of fear about relapse was noted in four out of the five participants. Two out of the five participants actually experienced relapse. P1 was already preparing for bad news before treatment completed.

'I just saw the look on her [consultant] face [at her end of treatment party] that it's not probably going to go that well because of her being high risk. So it was all undercut with the feelings of the fear of it coming back' (P1).

There was a feeling of shock and, in contrast to $\mathrm{P} 1$, a lack of preparation in $\mathrm{P} 2$ when her son received a second diagnosis of a different cancer as it came only six weeks after treatment completion.

'I think we were a little naïve and blasé around him responding well. That's fine, once it's over and done with we can continue and carry on. We weren't prepared in any way' (P2).

P3 and P5 acknowledged their active blocking of difficult feelings.

'I'm probably not the best person to ask because I block out things I don't want to think about' (P3).

'There's this constant fear, but I'm trying to ignore it all the time' (P5).

\section{Superordinate theme 3: Feelings since finishing treatment}

\section{Subordinate theme 3.1: Changed self}

All participants felt that they were changed in some way as a result of their child's cancer diagnosis. Although we have distinguished below between 'philosophical' and 'emotional' self, some responses clearly echo both.

\section{Sub-subordinate theme 3.1.1: Philosophical self}

All participants related specifically to how they have changed their thinking or behaviour in some way since their child finished treatment. P2 focussed on her need, on treatment 
completion, to have a substantial amount of space away from her normal day-to-day work in order to process what she had been through. P3, P4 and P5 note how they have changed their behaviour pattern.

'I've got absolutely no interest in worrying about trivial things... I feel that's a real positive. I'm so much more chilled out because it's just kind of made me re-focus on really what is more important and I know that might sound a bit cliché but it really is. I have, I'm not worrying about other things... I start getting philosophical about how long any of us have got left. I will just make it as happy and enjoyable and all the rest of it' (P5).

'I used to think, don't cry in-front of your children, because you come across as weak... but now I just think it's not normal to not cry. Crying is a release of emotions. So, when I feel I need to cry, I cry, and if the kids see me crying, I'd just say, sorry I'm having a bad day' (P4).

'It just changes you, I think. I'm still probably too much of an indulgent mum, so I might let him get away with more than he would do otherwise, but I just try to get the balance right' (P3).

\section{Sub-subordinate theme 3.1.2: Emotional self}

Four out of the five participants have continued experiencing strong emotions after their child finished treatment which they feel has changed them. P1 has been left experiencing frequent severe panic attacks.

'I just feel like a shadow of myself you know. I feel really ill most mornings when I wake up and it's hard to try and get through, but once you get yourself going, you're alright' (P1).

Lack of tolerance is noted in P3. 'I'm not very tolerant anymore' (P3) and anger is clearly still evident in participant four.

'I've got a heap of anger inside me that I don't really know what to do with. I've like been through two years of complete hell. And we've come out of it you know and she's ok. She's not got cancer anymore but she's damaged. That's the bit that you can't prepare for... it's a life changer. I've got a mentally and physically disabled child now, and I do worry about her future... I'm finding it hard to accept her as the person that she is now' (P4).

P5 talks about needing to be careful about getting too positive. 
'In the back of my head. I'm thinking if you get too positive, you're getting cocky and, and if you get cocky, things happen' (P5).

Strong emotions are still very much present in four of the five participants. P3 shares,

'I still get really emotional. Just years later, it's like you need some sort of release 'cos you just carry on. You pretend everything's fine and then the littlest thing just sets you off... It's three and a bit years ago since he finished his chemo and almost three years from getting his port-a-cath out and it feels like yesterday (P3).

\section{Subordinate theme 3.2: Longing for normality}

Four out of the five participants expressed a clear longing for a sense of normality to return once their child had completed treatment for cancer. P1 knew they were a high risk for relapse. Even after relapse, they currently continue to focus on attempting to maintain a sense of normality despite huge difficulties.

'It's just we never expected it to go on for so long... with that length of time and stay normal... I think they want her to have a normal life at school, which we want as well, but there's huge considerations isn't there' (P1).

P2 also experienced relapse.

'Towards the end of the first diagnoses and treatment the first time round we were really positive because he was back in school full-time, family life had gone back to normal except for the fortnightly check-ups... so we were almost getting our lives back together... it was a complete shock when he got a new diagnosis within a matter of weeks [of finishing treatment]' (P2).

After completing their second treatment protocol, the family's aim was again to retrieve a sense of normality.

'We've got straight into normality again, but it's taken a while to get to that stage, it took a good 12 months to start to feel like OK' (P2).

Participant four recognises that her longing for normality as they knew it will never be an option.

'It's tough, it's tough, a lot of mixed emotions emotions that I didn't think I would have I guess, 'cos I just thought, everything's just going to jump back into how it used to be afterwards, but it's not like that' (P4).

P5 attempts to create their previous normality despite her son's new difficulties. 
'I don't want him to feel different, like he has to be treated any differently you know... I've tried to give him as much freedom as possible, that he doesn't feel like he's been held back at all' (P5),

whilst clearly acknowledging that their normal now is very different.

'I do think that our normal is totally different to what it was. I am just kind of doing things to make their lives more enjoyable and not worrying too much about practicalities of everyday life' (P5).

There is also a sense of vulnerability.

'As lovely as that feels getting back to a bit of normality, I do feel a little bit exposed' (P5).

\section{Subordinate theme 3.3: Sense of abandonment / limbo}

\section{Sub-subordinate theme 3.3.1: Of self}

Two participants emphasised their sense of feeling in limbo.

'I just think about what those families who have lost their children are going through, but for us, ours has never ended. It's like we're just in limbo all this time... I'm either at home waiting for her next illness or phone-call from school, but thankfully they are getting less' (P1).

'You do feel like you're out on a limb, you do feel a bit isolated and I wasn't sure what they really meant by that, but I get where they're coming from now... I know I'm in complete limbo now' (P5).

\section{Sub-subordinate theme 3.3.2: From hospital}

Four of the five participants felt some sort of abandonment from the hospital.

'I do feel a bit like, who the hell do I phone in an emergency? Who do I ring? I rang the ward about something and it was like, you shouldn't be ringing us, you should be ringing... and I felt they thought I was expecting special treatment, and it was just, I didn't know who to ring, you know' (P5).

During treatment, the hospital was described as a security blanket. 
'It was definitely a security blanket, that I could just phone or shout someone, and just say I'm not sure about this... I just feel I need someone to just constantly say everything's still fine. Every three months just seems so frightening. Could do with weekly scans to know that he's ok' (P5).

The difference post-treatment was echoed by P4.

'Afterwards you are literally thrown out of the door into the big, bad world and you're supposed to go back to work and everything's supposed to carry on, but nothing is the same at all' (P4).

Due to area boundaries, P1 was not able to access some services post-treatment.

'I had to sort it out myself which drives me mad... I'd just been thrown into this world of adrenal insufficiency' (P1).

which resulted in undue stress. 'You worry you miss anything' (P1).

\section{Sub-subordinate theme 3.3.3: From friends}

Three participants focussed specifically on friendship groups.

'You lose all your friends and you feel yourself alone all of a sudden' (P1).

She later seemed to answer her own question with a possible reason why things changed.

'Your friends are pushed out I suppose. You don't realise you're pushing them out, then realise that you should have probably involved them a bit more, but it was tough at the time and now the time has gone and it's tough to get back in touch with them' (P1).

P5 also relates to changes in friendships.

'We seem to have developed a whole new circle of friends... but our really close friends, we haven't seen any of them in the whole time and that's kind of made us re-evaluate things' (P5).

P4 talked more about a lack of understanding from friends rather than a feeling of abandonment.

'It's tough, especially when your friends say to you, well she's not got cancer anymore, now what you stressing out about? And you just think if only you knew, but you don't explain to people because you can't put into a 20-minute conversation how bad things are. She's talked about killing herself because I'm not the person I used to be, I can't do this and I can't do this and I don't fit in with my school friends' (P4). 


\section{Subordinate theme 3.4: Underlying continued fear}

All participants touched upon a continued underlying fear. This was present regardless of the length of time spent off treatment. P3 and P4 acknowledged that although they were a number of years off treatment, the uncertainty is still there.

'Four years on from treatment and even now I don't feel prepared for what's going to come in the future' (P4).

P5 talks about trying to ignore her feelings but finds that the fear increases before a scan.

'At the back of my mind, there's five years of scans (emotion) and I don't want to constantly be thinking, in three months we'll find out if it comes back. I don't think I could cope with five years of that, so I'm trying to almost ignore' (P5).

She also talks about a fear of statistics.

'There's still only a 50/50 chance he's going to survive. I remember being really angry about that... I've got to stop looking at statistics... I think the more success stories I read, statistically that this one might not be a success' (P5).

P3 also picks up on what she describes as 'scanxiety'.

'When there are scans, I really need to be there in-case there is anything missed. It's just important' (P3).

P2 suggests that fear decreases as time goes on but that it never really disappears.

'As those check-ups become further apart, you sort of get a little bit of confidence but then also a little bit wary... are we going to miss anything?' (P2).

Here, she links the difference in support between on-treatment and post-treatment.

'Not getting the reassurance like you do when treatment finishes and the further you get away from the finish date and the stopping of visits and appointments... it's like trying to put that at the back of your mind and any worry that might come up if he has a cough or cold, is there a bruise? Check on that bruise. It's gradually fading now but, but it's still there... but you are always aware of the signs to look out for' (P2). 
P1 shows an ongoing heightened fear that is affecting her day to day post-treatment. Her experience of childhood cancer has been, and continues to be, relentless.

'I'm like, trying to be there for my daughter and strong, but we've gone through so much... still really intensive you know, massive treatments and things, there hasn't been a day when it's stopped at all' (P1).

\section{Subordinate theme 3.5: Effect on siblings}

Four of the five participants have more than one child. P2 has a much older sibling so there was less need for childcare. P3 reflected on her guilt at being less available for her daughter.

'She probably did find it hard when we left her, but she sort of got a new normal. She absolutely did adapt' (P3).

P4 talks about trying to give her other child more attention now.

'I find I give more attention to XXX now because YYY had so much attention when she was poorly... I felt like I abandoned XXX for the first three months... I guess that's being a mum isn't it, constantly beating yourself up. I just completely forgot about the fact that I had another child' (P4).

P5 talks about the changes she is seeing in her other child's behaviour.

'I'm really conscious that he's done really well, he's fantastic, but I'm noticing a change now. He's getting frustrated really easily. He's getting into a fight when I leave the house and I think he's only 5, and he's seen all kinds of horrors' (P5).

\section{Subordinate theme 3.6: Side-effects of treatment}

All five participants talked about the debilitating side-effects of the treatment for cancer. Three out of the five referred to the side-effects being worse than the actual cancer itself. P1 discusses the former and continued ongoing numerous side-effects seven years since diagnosis.

'The protocol is really intense. That made her really poorly and she had a stroke from one of her chemo' (P1).

She also experienced an eight-hour seizure. 
'I knew something was going to happen and she went into full seizure... so he hit the code button and the doors of the room just flew open and about 20 doctors just ran in... they worked on her straight away and she stopped breathing... it was unbelievable and it was just because we were just in the right place at the right time... she stayed in a coma for four or five days, it's bit of a blur. She seized for eight hours continuously' (P1).

She then talks of a miraculous recovery.

'I'll never forget when they pulled the tube out and she started to come round and she saw me. The first thing I think she said when she woke up was, mummy am I going to die?' (P1).

However, this has left her with numerous difficulties post-treatment.

'We are at the point where she has got quite serious graft versus host disease... [Also] She had an emergency operation and that's left her with a limp, so mobility is a bit of a struggle' (P1).

P2 also talks about a medical break-through.

'He had an underlying chest infection that we didn't know about and they said that his immunity is that weak that if we don't give something it could take hold of him... [the doctor] said he has never seen results like it and he's gone from strength to strength' (P2).

P3 talks about her son's impaired sight due to the treatment. The huge effect of treatment is emphasised through P4.

'I'm not worried about cancer because that's done now. It's just the damage that is done now... it's never-ending and it's a real drain for me as well' (P4).

P5 also talks about how her son's cancer seemed secondary to the side-effects.

'It almost seemed like his treatment was secondary to the problems that he had with what turned out to be hydrocephalus and the shunt, the shunt malfunctions and infection, infection, infection, sepsis, all his lines taken out, all his lines put back in, you know... [Also] he lost his sight for about 36 hours which frightened me because they couldn't work out why' (P5).

\section{Subordinate theme 3.7: Hope}


Despite the trauma that all participants have been through over an extended period of time, four participants intimated an element of hope through their adversity. This also links with the theme of wanting to help others.

'Hopefully at some point I'll be able to go out and get a little job, and I need that because it will be a complete distraction. My mind will be somewhere else' (P1).

"Me and my husband were really lucky that we had each other" (P2).

"We did it between us. We had an older son and we had to manage that home life and be here for him and for our own sanity as well. We needed to have that break away from the hospital...' (P2).

\section{Superordinate theme 4: Support}

Participant two explained that her support came from her family and that seemed to be enough. She did acknowledge, however, that counselling would probably help (see 3.4 .1 below).

'We have had such a good network of family and friends that have just been our saviour really and have been there for us' (P2).

Participants three and five found support from other families going through a similar situation, helpful.

'It's really nice to talk to his mum who has been through exactly the same thing... you feel like you've got a new support network... I think knowing that you're not alone is important, finding some sort of network of people who sort of get it' (P3).

'I ended up chatting to someone who lives in [place], a mum, and, and, her journey, her situation, set of circumstances, is almost identical to ours...he didn't survive um and I've never met her but we message each other daily almost' (P5).

\section{Subordinate theme 4.1: Recognition should really access support}

There is a recognition from all participants that accessing support would actually be beneficial.

'Any mums going through it now, I would definitely advise to take them up on the offer [of support] and try and share the load' (P1). 
'I did it years ago [accessed counselling] when my sister passed away with breast cancer. I probably need it more now, but I felt I could emotionally deal with it' (P2).

'It hadn't even occurred to me. Are there any lines of support for parents, do you know?... I sort of think if he's alright now what right have I got not to be ok? I just get a bit weepy sometimes and you know I can be watching utter nonsense on the tele and tears will be flowing' (P3).

'I've got a lot of mixed emotions going on and I guess I probably still need some help' (P4).

'I probably, in my head, think, actually you do need to get some support just to actually process what's just happened...' (P5).

\section{Subordinate theme 4.2: Wanting to help others}

Two participants talked specifically about wanting to help others

'We both wanted to help families going through that situation... I'd always hoped that we'd have our own charity to do it, but it's taken so much out of me that I find it very difficult...' (P1).

'I sort of gravitate towards them [other mums who have experienced childhood cancer] like I wonder whether I can give them some sort of help or advice that I could have used back in the day when XXX was having his treatment' (P3).

\section{Discussion}

It is clear from both the literature (e.g. Wakefield et al., 2011; Ljungman et al., 2018) and the data that transitioning from treatment to after-care, particularly for mothers, despite the expectation of initial relief, is also accompanied by very mixed feelings ( $P 1, P 2, P 3, P 5)$. There are elements of both 'elation' and 'fear'. However, the end date is still an important milestone, that, whether celebrated or not, remains a clear memory for mothers (P3, P4). Fear already appears to be present before treatment has completed (Rodriguez et al., 2012). These feelings link very closely with concern about the disease returning (P1, P2, P3, P5). 
Joy doesn't appear to be an instant and natural feeling once the cancer drugs are stopped. It takes time to feel safe after such intensive and life-threatening procedures (Vrijmoet-Wiersma et al., 2008). In-fact, only one participant talked about it being behind them now (P2). Instead, the data encompassed the notion of a 'changed-self'. Participants spoke positively about not worrying about 'trivial' things in life (P5) or having strengthened relationships as a result of their experience (P2). There is also a focus on wanting to help others (P1, P3). This concurs with Barakat et al.'s (2006) notion of post-traumatic growth and with Hone's (2017) exploration of resilience. Getting back to a sense of normality was also intimated. However, this doesn't always happen straight away (P2). The data also concur with Earle et al.'s (2007) findings that families accept a different normal, with a changed perception of what is now classed as normal. The data here, however, also show an element of grief for a previous life that has now gone forever (P1, P4). There also appears to be an expectation from the wider community that once treatment has finished, everything can now go back to normal, and this causes frustration (P1, P4).

The element of experiencing joy does seem to be overshadowed by a frequent and overwhelming sense of fear and distress (P1, P3, P4, P5). The disruption to the whole family group when a child is going through treatment for cancer is clearly extensive (Zheng et al. 2018). Often, children's physical and emotional symptoms of distress continue far after active treatment has completed (Li et al., 2010) and this affects a mother's own emotional wellbeing. Their strong emotions can continue post-treatment and can often be debilitating (P1, P4). There is also a real sense of abandonment, both from the hospital (P1, P2, P4, P5) and from friends, which causes distress (P1, P4, P5). The marked decrease in the number of medical visits as the hospital routine changes, results in the move away from the 'security blanket' of the hospital setting when post-treatment status is reached. Instead of having the expert medical team 'on tap', Kazak et al. (1997) explain the associated parental fear when their child 
comes down with a cold or displays symptoms that were closely linked to diagnosis (e.g. paleness) leading to their need for reassurance (P2). In relation to friendships, there was a lack of understanding by their support network and caused significant distress (P1, P4, P5). This concurs with Norburg and Green's (2007) research. Instead, it was explained that different friendship groups tended to form after diagnosis (P1, P3, P5). Support was often gained by families who were experiencing similar difficulties and this became mutually beneficial. Strong emotions were also associated with abandonment, not of others this time, but from the mothers themselves, in relation to caring for siblings (P3, P4, P5). Alderfer and Kazak (2006) recognise that siblings are often affected by a childhood cancer diagnosis. This clearly resonates within the current study. Feelings of guilt and sadness (P3) and a sense of abandonment $(\mathrm{P} 3, \mathrm{P} 4)$ have been mentioned, together with noticeable changes in sibling behaviour (P5). As side-effects of treatment are common, new medical concerns continue to be a big focus post-treatment (P1, P3, P4, P5). The data show that after overcoming one hurdle, four out of the five children were faced with new difficulties. This is clearly shown to have an impact on the mothers' emotional wellbeing. Cancer was frequently seen as 'secondary' (P1, P4, P5). The recognition of changed lives was very evident (P1, P3, P4, P5) and all possessed an underlying sense of sadness that can readily be identified with strong feelings of loss and sorrow. Continued fear post-treatment seems to link with an avoidance or blocking of feelings but also a feeling of hypervigilance (P1, P3, P5). Bruce (2005) explores this in relation to post-traumatic stress symptoms. Uncertainty of what the future will bring seems also to link with their feelings of being in 'limbo' (P1, P5). Ljungman et al. (2018) focus on emotional avoidance. There is a sense that this is a necessary coping mechanism during the treatment phase. However, if this behaviour continues post-treatment, there is a possibility of mal-adaption. Blocking out pain was a recurrent method of coping (P1, P3, P5). 
It was clear that four out of the five participants would definitely benefit from further support to process their issues. There was a recognition from all participants that they could probably benefit from talking to someone. However, they all put their children's needs before themselves. As support wasn't readily available or easily accessible post-treatment, there was a tendency to believe that they just had to 'keep on pedalling' (P4). Stuber et al. (1996), in recognising the debilitating effect of post-traumatic stress symptoms, conclude that giving parents an opportunity to discuss psychological concerns may help to reduce levels of anxiety and distress. Wakefield et al. (2011) clearly acknowledge the importance of psychosocial interventions to help alleviate fear of recurrence, physical and emotional fatigue, loneliness, social isolation and parenting issues (all evident in the present study). However, they later note that it isn't easy asking for help (Wakefield et al. 2013). The data demonstrate that making counselling support available in this way so that mothers don't have to search for help would be extremely valuable, not just during the transitioning to after-care services, but also at any time post-treatment, without stipulating a time limit. Whilst Wakefield et al. (2015) and Wikman et al. (2018) show that the need is there, the exact type of support is underresearched. Young (2018) does explore counselling strategies for parents during their child's treatment, but there appears to be a gap exploring the effect of counselling post-treatment. The data indicates that it isn't necessarily about length of time post-treatment that is the key to understanding a mother's emotional wellbeing, as four of the five participants showed strong emotion and talked about the need to block their feelings in order to cope. It is more about being able to have access to a safe and accepting space, in the form of counselling, to be able to, when they feel ready, 'unblock' what they have buried and begin to face their emotions in-order to release all the pain and hurt that has been absorbed whilst caring for their child through cancer. Although common themes thread throughout all participants' stories, it was noticeable that each mother focused on her own unique journey. Rather than 
attempting to fit a mother's experience into a particular level of distress and associated intervention, a person-centred approach would probably enable mothers to have the necessary space to begin a process of coming to terms with all that they have experienced during their child's cancer journey and to look to the future through a 'different lens'.

\section{Conclusion}

The study is small-scale, consisting of only five participants. It is clearly not appropriate to generalise the results too universally. However, we get a flavour of a handful of mothers' views and experiences so that further discussion and reflections can ensue. As a cancer diagnosis is so complex, made up of different treatment regimens to cover the numerous different diagnoses, it is also not easy to compare participants' experiences like for like. Further, as a specific time that participants had to have reached post-treatment wasn't stipulated (due to not wanting to exclude someone who may be struggling years following treatment completion), the range was quite broad (two months to five-and-a half years).

The primary nature of the research has allowed for an in-depth encounter into five mothers' lives, where they reflected upon an incredibly painful time in their lives and how their experiences continue to affect them. This research clearly demonstrates that childhood cancer has changed all participants in different ways. Regardless of how long post-treatment their child was, in relation to their cancer journey, strong emotions are still present in four of the five participants. The further the length of time mothers were, from treatment completion, did not necessarily mean that they were more grounded in their emotional wellbeing. Blocking of strong feelings was spoken about frequently as a coping mechanism. All participants reflected that counselling post-treatment would have probably been beneficial for them. There was an uncertainty, however, as to how to access this type of support posttreatment. It was suggested, too, that having to return to the hospital environment where 
strong emotions were experienced didn't feel comfortable after a time. Offering personcentred counselling as a matter of course for mothers, once they have had time to start getting back into a routine that doesn't include regular medical appointments and aggressive treatment regimens, and which is away from the hospital setting, will help them process their emotions in a way that will strengthen their coping for the future. Giving voice to these mothers was very important for them, for other professionals and for the parents of children with cancer and others who are parts of their networks. 


\section{References}

Alderfer, M. A., \& Kazak, A. E. (2014). Family issues when a child is on treatment for cancer. In R. T. Brown (Ed.), Comprehensive handbook of childhood cancer and sickle cell disease: A biopsychosocial approach (pp. 53-74). New York: Oxford University Press.

Barakat, L. P., Alderfer, M. A., \& Kazak, A. E. (2006). Posttraumatic growth in adolescent survivors of cancer and their mothers and fathers. Journal of Pediatric Psychology, 31(4), 413-419. https://doi.org/10.1093/jpepsy/jsj058

Bruce, M. (2005). A systematic and conceptual review of posttraumatic stress in childhood cancer survivors and their parents. Clinical Psychology Review, 26(3), 233-256. https://doi.org/10.1016/j.cpr.2005.10.002

Children's Cancer and Leukaemia Group. (2019). Retrieved August 17, 2019, from https://www.cclg.org.uk/Childhood-cancer

Earle, E. A., Clarke, S. A., Eiser, C., \& Sheppard, L. (2007). "Building a new normality": Mothers' experiences of caring for a child with acute lymphoblastic leukaemia. Child: Care, Health and Development, 33(2), 155-160. https://doi.org/10.1111/j.13652214.2006.00638.x

Hone, L. (2017). Resilient grieving: Finding strength and embracing life after a loss that changes everything. New York: The Experiment.

Kazak, A. E., Barakat, L. P., Meeske, K., Christakis, D., Meadows, A. T., Casey, R., \& Stuber, M. L. (1997). Posttraumatic stress, family functioning, and social support in survivors of childhood leukemia and their mothers and fathers. Journal of Consulting and Clinical Psychology, 65(1), 120-129. https://doi.org/10.1037/0022-006X.65.1.120

Li, H. C. W., Chung, O. K. J., \& Chiu, S. Y. (2010). The impact of cancer on children's physical, emotional, and psychosocial well-being. Cancer Nursing, 33(1), 47-54. https://doi.org/10.1097/NCC.0b013e3181aafOfa

Ljungman, L., Cernvall, M., Ghaderi, A., Ljungman, G., von Essen, L., \& Ljótsson, B. (2018). An open trial of individualized face-to-face cognitive behavior therapy for psychological distress in parents of children after end of treatment for childhood cancer including a cognitive behavioral conceptualization. Peer J, 6, 45-70. https://doi.org/10.7717/peerj.4570

Marusak, H. (2018). Understanding the psychological effects of childhood cancer. Retrieved August 17, 2019, from https://www.scientificamerican.com/article/understanding-thepsychological-effects-of-childhood-cancer1/

National Cancer Institute. (2019). Understanding Cancer. Retrieved August 23, 2019, from https://www.cancer.gov/about-cancer/understanding/what-is-cancer

Norberg, A. L., \& Green, A. (2007). Stressors in the daily life of parents after a child's successful cancer treatment. Journal of Psychosocial Oncology, 25(3), 113-122. https://doi.org/10.1300/J077v25n03_07 
Rodriguez, E. M., Dunn, M. J., Zuckerman, T., Vannatta, K., Gerhardt, C. A., \& Compas, B. E. (2012). Cancer-related sources of stress for children with cancer and their parents. Journal of Pediatric Psychology, 37(2), 185-197. https://doi.org/10.1093/jpepsy/jsr054

Smith, J., Flowers, P., \& Larkin, M. (2009). Interpretative Phenomenological Analysis: Theory, method and research. London: Sage.

Stuber, M. L., Christakis, D. A., Houskamp, B., \& Kazak, A. E. (1996). Post-trauma symptoms in childhood leukemia survivors and their parents. Psychosomatics, 37(3), 254-261. https://doi.org/10.1016/S0033-3182(96)71564-5

Vrijmoet-Wiersma, C. M. J., van Klink, J. M. M., Kolk, A. M., Koopman, H. M., Ball, L. M., \& Maarten Egeler, R. (2008). Assessment of parental psychological stress in pediatric cancer: A review. Journal of Pediatric Psychology, 33(7), 694-706. https://doi.org/10.1093/jpepsy/jsn007

Wakefield, C. E., McLoone, J. K., Butow, P., Lenthen, K., \& Cohn, R. J. (2011). Parental adjustment to the completion of their child's cancer treatment. Pediatric Blood \& Cancer, 56(4), 524-531. https://doi.org/10.1002/pbc.22725

Wakefield, C. E., McLoone, J., Butow, P., Lenthen, K., \& Cohn, R. J. (2013). Support after the completion of cancer treatment: perspectives of Australian adolescents and their families. European Journal of Cancer Care, 22(4), 530-539.

https://doi.org/10.1111/ecc.12059

Wakefield, C. E., Sansom-Daly, U. M., McGill, B. C., McCarthy, M., Girgis, A., Grootenhuis, M., \& Cohn, R. J. (2015). Online parent-targeted cognitive-behavioural therapy intervention to improve quality of life in families of young cancer survivors: study protocol for a randomised controlled trial. Trials, 16(1), 153. https://doi.org/10.1186/s13063-0150681-6

Wikman, A., Kukkola, L., Börjesson, H., Cernvall, M., Woodford, J., Grönqvist, H., \& von Essen, L. (2018). Development of an internet-administered cognitive behavior therapy program (ENGAGE) for parents of children previously treated for cancer: participatory action research approach. Journal of Medical Internet Research, 20(4), 133. https://doi.org/10.2196/jmir.9457

Young, T. (2018). Counselling parents of children with cancer: Therapeutic considerations and strategies. Journal of Mental Health Counselling, 40(3), 185-198.

Zheng, D. J., Lu, X., Schore, R. J., Balsamo, L., Devidas, M., Winick, N. J., \& Kadan-Lottick, N. S. (2018). Longitudinal analysis of quality-of-life outcomes in children during treatment for acute lymphoblastic leukemia: A report from the children's oncology group AALL0932 trial. Cancer, 124(3), 571-579. https://doi.org/10.1002/cncr.31085 